\title{
Enhancing the technological plasticity of the AlMgSi0.5 alloy strips when drawing in a rolling die
}

\author{
A. N. Abramov ${ }^{\dagger, 1}$, A. V. Botkin ${ }^{1,2}$, V. Yu. Sholom ${ }^{1}$, K. A. Abramov' ${ }^{1}$, E. V. Varenik ${ }^{1}$ \\ †Abramov@rosoil.ru
}

${ }^{1}$ Ufa State Aviation Technical University, 12 K. Marx St., Ufa, 450000, Russia

${ }^{2}$ Bashkir State University, 32 Zaki Validi St., Ufa, 450076, Russia

\begin{abstract}
A testing bed was developed and manufactured for drawing rods and strips of various sections in the rolling die. The testing bed allows measuring the friction strength at stopped rolls, the normal force at the standing rolls and the drawing force in the drawing process. The influence of friction force on the parameters of the load and the deformation extent, as well as the deformation amount for the alloy AlMgSi0.5 was established. The influence of multiple deformations on the maximum of deformation to failure and on the drawing stress at different friction conditions was established. It was found that the multiple drawing increased the technological plasticity, but did not affect the drawing stress at the moment of the failure of the AlMgSi0.5 ingots. It was shown that the drawing stress at the moment of the failure of the sample was similar both for the absence and for the presence of sliding friction. Multiple deformation influenced the amount of deformation maximum to failure, but it has no effect on the drawing stress both in the absence and in the presence of sliding friction. The possibility of experimental estimation of the strain increase reserve during drawing by reducing the influence of the friction force was shown. A calculation method for estimating the strain reserve at drawing was proposed and experimentally tested. It was experimentally shown that the difference in the rolling friction force and the sliding friction force depended on the degree of deformation per pass.
\end{abstract}

Keywords: friction force, roller die, friction coefficient, the degree of deformation, failure, scoring, lubricant.

УДК: 621.7

\section{Повышение технологической деформируемости полос} из сплава АД-31 при волочении в роликовой волоке

\author{
Абрамов А. Н. ${ }^{\dagger, 1}$, Боткин А. В. ${ }^{1,2}$, Шолом В. Ю. ${ }^{1}$, Абрамов К. А. ${ }^{1}$, Вареник Е. В. ${ }^{1}$ \\ ${ }^{1}$ Уфимский государственный авиационный технический университет, ул. К. Маркса, 12, Уфа, 450000, Россия \\ ${ }^{2}$ Башкирский государственный университет, ул. Заки Валиди, 32, Уфа, 450076, Россия
}

Для определения интегральных значений силы трения, нормальной нагрузки и силы волочения был разработан специальный стенд, на котором реализована схема волочения заготовок в виде прутков и полос различного сечения с использованием роликовой неприводной волоки. Показано влияние силы трения на энергосиловые параметры и степень деформации до разрушения при волочении заготовок в виде полос из алюминиевого сплава АД-31. Установлено влияние дробности деформации на степень деформации до разрушения и величину напряжения волочения при различных условиях трения между заготовкой и инструментом. При этом выявлено, что дробность деформации повышает технологическую деформируемость заготовок, но не влияет на величину напряжения волочения в момент разрушения заготовок из алюминиевого сплава АД-31. Показано, что величина напряжения волочения в момент разрушения образцов при наличии трения скольжения (ролики застопорены), и в его отсутствии (ролики свободно вращаются) одинаковая. Другими словами, дробность деформации влияет на величину предельной степени деформации до разрушения, а на разность напряжений волочения в условиях деформирования с трением скольжения и «без него» в момент разрушения не влияет. Показана возможность экспериментально-расчетной оценки резерва увеличения степени деформации при волочении за счет уменьшения влияния силы трения. Предложена и опробована методика экспериментально-расчетной оценки резерва увеличения степени деформации при волочении за счет уменьшения влияния силы трения. Экспериментально показано, что разность сил трения скольжения и качения при волочении полосы в застопоренных и свободно вращающихся роликах зависит от степени деформации в проходе.

Ключевые слова: сила трения, роликовая волока, разрушение, напряжение волочения, дробность деформации. 


\section{1. Введение}

Одним из основных показателей пригодности металла, предназначенного для изготовления деталей методами холодного пластического деформирования, является технологическая деформируемость, которая характеризует способность металла изменять свою форму при обработке давлением без нарушения сплошности. Количественно деформируемость тела можно характеризовать величиной допустимой деформации тела до начала образования трещин, количеством образовавшихся трещин и их размеров при данной величине произведенной деформации или до полного разрушения тела [1].

Важными факторами, влияющими на технологическую деформируемость, являются сила трения между заготовкой и инструментом и дробность деформации. Силу трения можно регулировать применением эффективных технологических смазок [2-6]. Известны работы [7], в которых снижение энерго-силовых параметров деформирования осуществляется за счет замены силы трения скольжения на силу трения качения.

Для количественной оценки параметров контактного взаимодействия в процессах обработки металлов давлением необходимо знать (измерять) величину силы трения и её изменение в процессе пластической деформации взависимости от режимов деформирования. Устройства для измерения сил трения непосредственно в процессе деформирования позволяют проводить комплексные исследования по оценке влияния температурно-скоростных и энергосиловых режимов деформирования различных материалов на показатели трения $[7,8]$. Кривая изменения силы трения в таких устройствах заметно реагирует на изменение условий трения. Такие устройства необходимы также для оценки свойств и эффективности применения технологических смазочных материалов для процессов объемной штамповки [7].

Увеличение дробности деформации уменьшает величину деформации за один цикл и, следовательно, уменьшает величину остаточных напряжений в рабочем участке заготовки, которые возникают во время деформации. Во время очередного цикла деформации происходит алгебраическое суммирование остаточных напряжений, полученных во время предыдущего цикла, с дополнительными напряжениями, появляющимися при деформации металла во время данного цикла. При этом величина продольного растягивающего напряжения, ограничивающего пластичность металла, уменьшается [9-14].

Целью работы является оценка резерва повышения технологической деформируемости при волочении полос из сплава АД-31 в роликовой волоке за счет изменения величины силы трения между заготовкой и инструментом.

\section{2. Методика исследований}

Оценку влияния степени деформации и вида смазочных материалов на силу деформирования, силу трения скольжения осуществляли при деформи- ровании алюминиевых полос различного сечения из сплава АД-31 (системы A1-Mg-Si с химическим составом по ГОСТ 4782-97) с условным пределом текучести 160 МПа и временным сопротивлением разрыву 216 МПа.

Силовые параметры волочения измеряли на специальном стенде для деформирования заготовок с использованием роликовой неприводной волоки (Рис. 1a), оснащенном датчиками силы. Длина заготовок составляла $300 \pm 0.1$ мм, толщина $2 \pm 0.1$ мм, ширина $25 \pm 0.1$ мм.

Горизонтальную составляющую силу реакции опоры ролика $N$ измеряли двумя датчиками силы 5 (Рис. 1b) мембранного типа, работающими на сжатие. Силу $R$ реакции опоры рычага, предотвращающего вращение ролика и создающего тормозной момент $M_{t o r}$, измеряли тензорезисторным датчиком силы, работающим на растяжение.

Результирующую силу трения скольжения рассчитывали, пренебрегая влиянием силы трения покоя в опоре ролика и принимая допущение, что линия действия результирующей силы нормальных элементарных сил на контактной поверхности заготовки и ролика пересекает ось вращения ролика под прямым углом (т.е. не создает крутящего момента относительно оси ролика), из равенства моментов $T_{s l} \cdot 0.5 D=R \cdot L$, где $T_{s l}$ - результирующая сила трения скольжения элементарных сил трения, действующих на контактной поверхности, $D$ - диаметр ролика, $L-$ длина рычага, предотвращающего вращение ролика, $R-$ измеренная экспериментально сила реакции опоры рычага.

Силу деформирования, с которой действует захват на заготовку при волочении, регистрировали датчиком силы, установленным на разрывной машине $[15,16]$.

Степень деформации определяли по формуле:

$$
e=\left|\ln \frac{h_{k}}{h_{0}}\right|
$$

где $h_{0}$ и $h_{k}$ - толщина заготовки до и после деформирования, соответственно.

Напряжение волочения определяли по известной формуле [17]:

$$
\sigma_{\mathrm{B}}=P_{\text {def }} / S
$$

где $P_{d e f}-$ сила деформирования (волочения), $S-$ площадь сечения заготовки после волочения.

При протягивании образцов в виде полос различного сечения на указанной установке применяли ролики диаметром 47 мм из стали ХВГ, с твердостью HRC 55-60 и шероховатостью поверхности $R_{a}=0.09$ мкм. Соотношение ширины к толщине заготовок в виде полосы было больше 3 , что обеспечивало при волочении деформированное состояние близкое к плоскому, а уширение полосы составляло не более $3 \%$.

Деформирование осуществляли двумя способами:

- образец деформировали с разными степенями обжатия до разрушения, а степень обжатия увеличивали через равные промежутки времени или расстояния (по меткам, нанесённым на боковой поверхности образцов) с помощью механической регулировки 


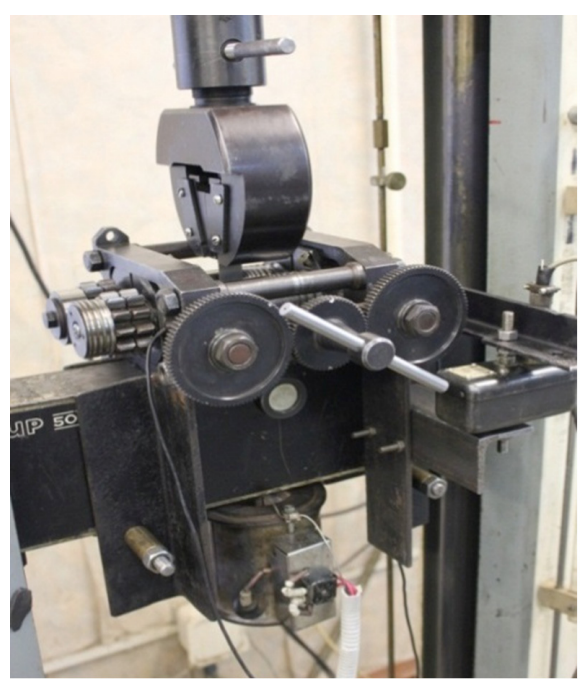

a

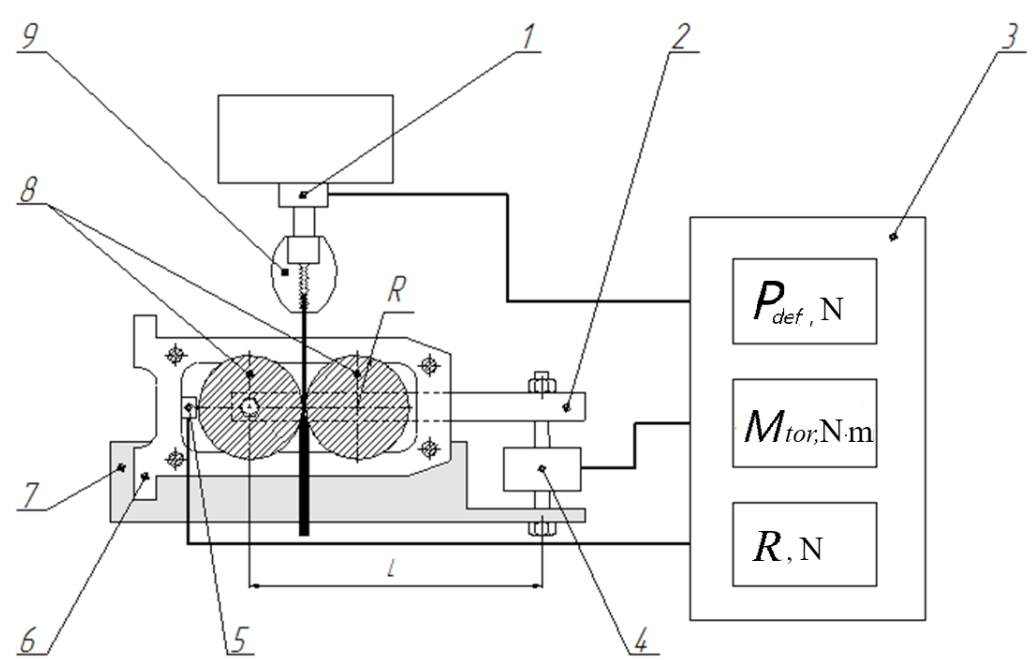

$\mathrm{b}$

Рис. 1. Внешний вид (а) и схема экспериментального стенда (b): 1 - датчик силы разрывной машины, 2 - рычаг механизма торможения, 3 - блок регистрации данных с датчиков силы, 4 - датчик силы реакции опоры рычага, предотвращающего вращение ролика, 5 - датчики силы, регистрирующие горизонтальную составляющую силу реакции опоры ролика, 6 - станина с подшипниками и механической системой регулировки зазора между роликами и зубчатой передачей, 7 - подвижная траверса разрывной машины, 8 - ролики, 9 - захват разрывной машины.

Fig. 1. Appearance (a) and the scheme of the experimental bed (b): 1 - the force sensor of the breaking machine, 2 - the lever of the braking mechanism, 3 - the data logging unit with force sensors, 4 - the reaction force sensor of the lever support, preventing the rotation of the roller, 5 - force sensors, registering the horizontal component of the reaction force of the roller support, 6 - the frame with bearings and mechanical adjustment system, 7-movable beam tensile machine, 8-rollers, 9-breaking machine.

расстояния между роликами. Если на первом образце разрушения не происходило, то деформировали второй образец.

- образец деформировали с одним заданным обжатием $\Delta h=0.2$ мм на всю длину. Перед каждым последующим деформированием степень обжатия увеличивали с помощью механической регулировки расстояния между роликами, и образец деформировали с добавленной степенью деформации на всю длину до разрушения. На каждую экспериментальную точку деформировали по пять образцов.

\section{3. Экспериментальные результаты и их обсуждение}

На первой стадии исследований определили область влияния сил трения скольжения и качения на силу деформирования. Для этого образцы деформировали по первому способу без нанесения смазочного материала, при свободно вращающихся роликах. Принималось допущение [9], что сила трения скольжения при этом отсутствует. Затем ролики стопорили и так же деформировали образцы до разрушения. На Рис. 2 показана область действия сил трения при деформировании полосы с разными степенями обжатия до разрушения без применения смазочных материалов.

Из приведенного рисунка видно, что замена силы трения скольжения на силу трения качения позволяет уменьшить силовые параметры волочения полос из алюминиевого сплава АД-31 от 30 до $62 \%$ и увеличить степень деформации образцов до разрушения на $43 \%$.

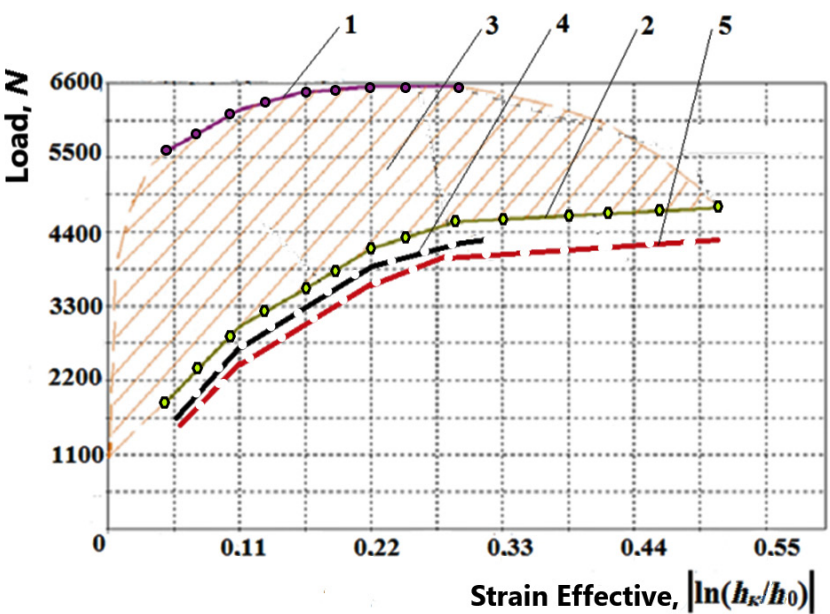

Рис. 2. Экспериментальная оценка влияния сил трения на силу деформирования при волочении полос из сплава АД-31 через роликовую волоку для различных степеней деформации и скорости деформирования $1.7 \times 10^{-4} \mathrm{M} / \mathrm{c}$ : 1 - без смазочного материала (ролики застопорены); 2 - без смазки (ролики свободно вращаются); 3 - область влияния сил трения скольжения на силу волочения (деформирования), 4 - ролики застопорены в «идеальных условиях» трения скольжения, 5- ролики вращаются в «идеальных условиях» трения качения.

Fig. 2. Experimental evaluation of the effect of friction forces on the deformation force when drawing strips of alloy AlMgSi0.5 through a roller die for different degrees of deformation and deformation rate $1.7 \times 10^{-4} \mathrm{~m} / \mathrm{s}: 1$ - without lubricant (rollers are stalled); 2 - without lubrication (rollers rotate freely); 3 - the area of influence of sliding friction forces on the drawing force (deformation), 4 - rollers are stalled in «ideal conditions» of sliding friction, 5 - rollers rotate in «ideal conditions» rolling friction. 
На Рис. 3 показан внешний вид заготовок из сплава АД-31 до деформации и после.

Придеформированииполоссприменениемсмазочных материалов различной природы, и при застопоренных роликах, значения сил деформирования попадают именно в область 3 , показанную на Рис. $2[15,16]$.

Ширина области 3 (разность сил деформирования при застопоренных и свободно вращающихся роликах) обусловлена разностью сил трения скольжения и качения. Это следует из анализа балансов работ.

$$
P_{1} \cdot V_{\text {def }}=W_{\text {def. } 1}+2 \cdot T_{s l} \cdot 0.5\left(V_{d e f}+V_{0}\right),
$$

где $P_{1}-$ сила деформирования при застопоренных роликах (Рис. 4), $V_{d e f}$ - скорость деформирования (скорость движения полосы на выходе из очага деформации), $W_{d e f .1}-$ мощность пластической деформации при застопоренных роликах, $T_{s l}$ - результирующая сила трения

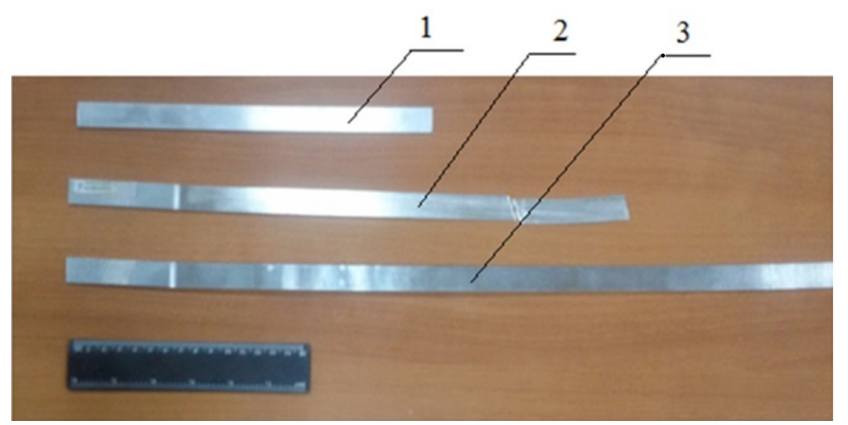

Рис. 3. Внешний вид заготовок из сплава АД-31: 1 - образец до деформирования, 2 - образец после деформирования без смазочного материала при застопоренных роликах, 3 - образец после деформирования без смазочного материала при свободно вращающихся роликах (трение скольжения отсутствует).

Fig. 3. Appearance of AlMgSi0.5 alloy ingots: 1 - specimen before deformation, 2 - specimen after deformation without lubricant when stalled rollers, 3 - sample after deformation without lubricant with freely rotating rollers (no sliding friction).

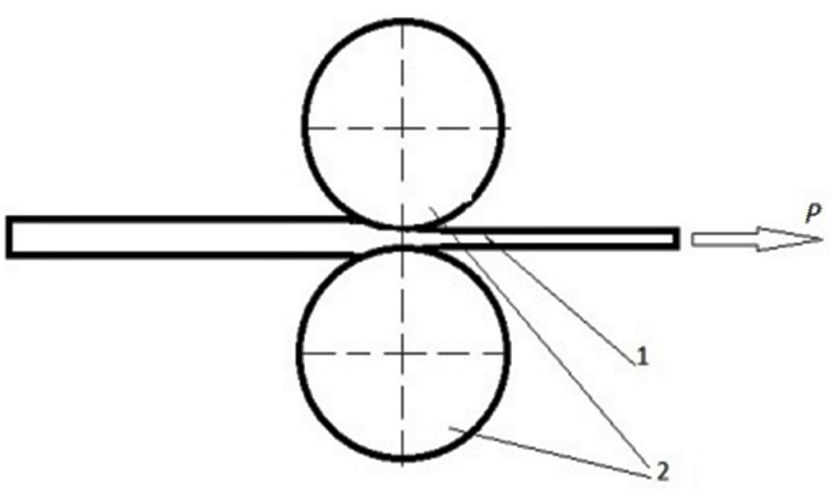

a скольжения, $V_{0}-$ скорость движения полосы на входе в очаг деформации.

$$
P_{2} \cdot V_{\text {def }}=W_{\text {def.2 }}+2 \cdot T_{\text {rol }} \cdot V_{\text {def }},
$$

где $P_{2}$ - сила деформирования при свободно вращающихся роликах, $W_{d e f .2}-$ мощность пластической деформации при свободно вращающихся роликах, $T_{r o l}$ - сила трения качения.

После интегрирования по времени выражения (3) и (4) преобразуются к виду

$$
\begin{gathered}
P_{1} \cdot L_{k}=A_{d e f .1}+2 \cdot T_{s l} \cdot 0.5\left(L_{k}+L_{0}\right), \\
P_{2} \cdot L_{k}=A_{d e f .2}+2 \cdot T_{s l} \cdot L_{k},
\end{gathered}
$$

где $L_{k}$ - длина полосы после волочения, $A_{d e f .1}-$ работа пластической деформации при застопоренных роликах, $A_{\text {def.2 }}-$ работа пластической деформации при свободно вращающихся роликах, $L_{0}$ - длина полосы до волочения.

Допуская равенство работ пластической деформации $A_{d e f .1}=A_{d e f .2}$ из (5) и (6) получаем

$$
P_{1}-P_{2}=\frac{\left(L_{k}+L_{0}\right)}{L_{k}} \cdot T_{s l}-2 T_{\text {rol }}
$$

Выражение (7) показывает, что с увеличением разности сил трения скольжения и качения увеличивается с точностью до коэффициента разность сил деформирования при застопоренных и свободно вращающихся валках.

Из выражения (5), используя расчетно-экспериментальные данные для силы трения скольжения $T_{s l}$, можно получить формулу для оценки силы $P$ деформирования полосы в идеальных условиях трения скольжения, т. е. при «отсутствии» трения скольжения

$$
P=P_{1}-T_{s l} \cdot \frac{\left(L_{k}+L_{0}\right)}{L_{k}}
$$

Используя формулу (8) построили графическую зависимость силы деформирования $P$ от степени деформации (кривая 4) на Рис. 2.

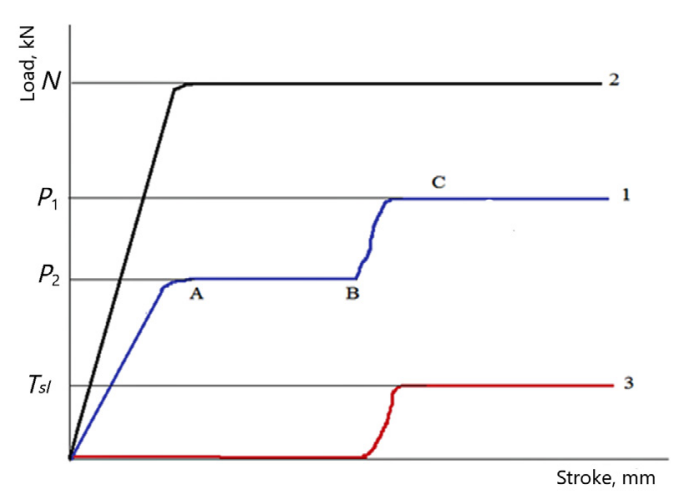

$\mathrm{b}$

Рис. 4. Схема деформирования (а): 1 - заготовка, 2 - ролики; графические зависимости силовых параметров деформирования для образцов в виде полос (b): 1 - сила деформирования $P_{1}$ - перемещение траверсы при застопоренных роликах, $P_{2}-$ сила деформирования при свободно вращающихся роликах; $2-$ нормальная нагрузка, $N$ - перемещение траверсы; $3-$ сила трения скольжения $T_{s l}$ - перемещение траверсы, на участке A-В ролики свободно вращаются, в точке В ролики стопорятся.

Fig. 4. Deformation scheme (a): 1-billet, 2-rollers; and graphic dependences of the deformation force parameters for the specimens in the form of strips (b): 1 - deformation force $P_{1}$ - traverse moving when the rolls are stopped, the deformation force $P_{2}$ when the rolls freely rotating; 2 - normal load $N-$ moving traverse; 3 - sliding friction force $T_{s l}-$ moving traverse, on the site A-B the rolls rotate freely, at the point $\mathrm{B}$ the rolls are locked. 
Для оценки силы деформирования $P$ полосы в идеальных условиях трения можно также использовать формулу (6) и экспериментальные данные измерения горизонтальной составляющей силы реакции опоры ролика $N$.

$$
P=P_{2}-2 \cdot T_{r o l},
$$

где значение силы трения качения можно рассчитать по известной формуле [17]

$$
T_{\text {rol }}=\frac{\mu \cdot N+f \sqrt{N^{2}+\left(0.5 P_{2}\right)^{2}} \cdot 0.5 d}{0.5 D}
$$

где $\mu-$ коэффициент трения качения, принимается равным 0.766 мм - половине длины проекции геометрического очага деформации на вертикальную ось (Рис. $1 b), f=0.01$ коэффициент трения в цапфах роликов $[18,19], d-$ диаметр цапфы ролика, $d=0.5 \mathrm{D}$, $D$ - диаметр ролика.

Используя формулу (9) построили графическую зависимость силы $P$ деформирования от степени деформации в идеальных условиях трения качения, т.е. при отсутствии трения качения (кривая 5) на Рис. 2.

Область, расположенная между кривыми 1 и 5, в интервале степеней деформации от 0.05 до 0.27 (Рис. 2) характеризует резерв увеличения степени деформации при волочении за один проход за счет применения смазочных материалов, уменьшающих влияние силы трения скольжения.

Влияние степени деформации на напряжение волочения полос из сплава АД-31 через роликовую волоку для различных контактных условий показано на Рис. 5.

Известно, что дробность деформации значительно увеличивает деформируемость заготовки [20,21]. Это справедливо, если процессу деформации металла предшествует разупрочнение, а сама деформация приближается к равномерной. Если указанное условие отсутствует, увеличение дробности деформации приводит к уменьшению пластичности металла [20,21].

По результатам проведенных экспериментов можно утверждать, что величина предельной степени деформации (до разрушения образца) при дробной деформации (Рис. 2 и 5), достигнутой при действии силы трения скольжения, и в ее отсутствии превосходит величину предельной степени при одном проходе более чем на 50\%. Разность сил трения скольжения и качения при волочении полосы в застопоренных и свободно вращающихся роликах зависит от степени деформации в проходе.

Кроме этого величина напряжения волочения в момент разрушения образцов при наличии трения скольжения, и в его отсутствии одинаковая. Другими словами, дробность деформации влияет на величину предельной степени деформации до разрушения, a на разность напряжений волочения между деформированием с трением скольжения и без него в момент разрушения не влияет.

Полученные результаты показывают, что управляя контактными условиями трения, например, путем применения смазочных материалов, можно значительно снизить влияние силы трения скольжения на силу

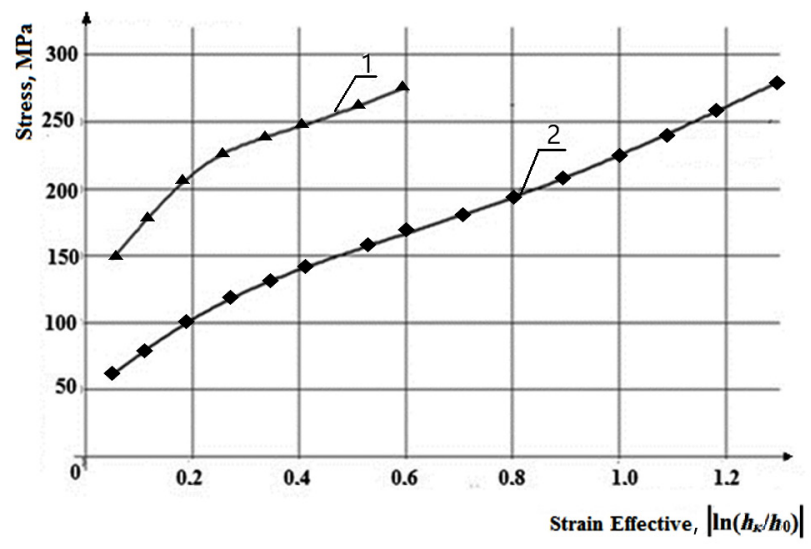

Рис. 5. Влияние степени деформации на напряжение волочения полос из сплава АД-31 через роликовую волоку для различных контактных условий: 1 - без смазочного материала, ролики застопорены, 4 прохода; 2 - без смазочного материала, ролики свободно вращаются, 8 проходов.

Fig. 5. The effect of the deformation degree on the drawing stress for AlMgSi0.5 alloy strips through the roller die for different contact conditions: 1 - without lubricant, the rollers are stopped, 4 passes; 2 - without lubricant, the rollers rotate freely, 8 passes.

деформирования и существенно увеличить предельную степень деформации до разрушения, т. е. повысить технологическую деформируемость заготовок при прочих равных условиях.

\section{4. Выводы}

1. Показано, что за счет управления силой трения скольжения можно снизить энергосиловые параметры волочения полос из алюминиевого сплава АД-31 на величину от 30 до $62 \%$ и увеличить степень деформации образцов до разрушения на $43 \%$.

2. Выявлено, что дробность деформации влияет на величину предельной степени деформации до разрушения, а на разность напряжений волочения между деформированием с трением скольжения и без него в момент разрушения не влияет.

3. Установлено, что дробность деформации не влияет на предельную величину напряжения волочения.

4. Показана возможность экспериментальнорасчетной оценки резерва увеличения степени деформации при волочении за счет уменьшения влияния силы трения.

\section{Литература/References}

1. M. Ya. Dzugutov. Napryazheniya i razryvy pri obrabotke metallov davleniyem. Moscow. Engineering (1974) 280 p. (in Russian) [М.Я. Дзугутов. Напряжения и разрывы при обработке металлов давлением. Москва, Metallurgiya (1974) 280 c.]

2. F.P. Bowden, D. Tabor. The friction and lubrication of solids. Oxford, Claredon Press (1954) 372 p.

3. A. Ya. Chasnikov. Razrabotka i vnedreniye effektivnykh tekhnologiy proizvodstva ploskogo prokata vysokoy tochnosti iz medi i yeye splavov na osnove izucheniya ikh 
fiziko-mekhanicheskikh svoystv i struktury: Dissertacija na soiskanie stepeni kandidata tehnicheskih nauk. Moscow (2006) 260 p. (in Russian) [А.Я. Часников. Разработка и внедрение эффективных технологий производства плоского проката высокой точности из меди и ее сплавов на основе изучения их физикомеханических свойств и структуры: дис. докт. техн. наук. Москва (2006) 260 с.]

4. P.I. Polukhin, G. Ya. Gong, A. M. Galkin. Soprotivleniye plasticheskoy deformatsii metallov i splavov. Moscow, Metallurgy (1983) 352 p. (in Russian) [П.И. Полухин, Г.Я. Гун, А.М. Галкин. Сопротивление пластической деформации металлов и сплавов. Москва, Металлургия (1983) 352 с.]

5. V.L. Popov. Mekhanika kontaktnogo vzaimodeystviya i fizika treniya. Ot nanotribologii do dinamiki zemletryaseniy. Moscow, Phismatlith (2013) 352 p. (in Russian) [В.Л. Попов. Механика контактного взаимодействия и физика трения. От нанотрибологии до динамики землетрясений. Москва, Физматлит (2013) 352 c.]

6. H. Valberg. Proceeding of International Conference "Latest Advances in Extrusion Technology and Simulation in Europe and Extrusion Benchmark". Bologna, Italy (2007) p. 9.

7. I.S. Aliyev, K. Kruger. KShP OMD. 1, 3 (2008). (in Russian) [И.С. Алиев, К. Крюгер. КШП ОМД. 1, 3 (2008).]

8. L. Dubar, A. Dubois, M. Dubar. Key Engineering Materials. 767, 42 (2018) Crossref

9. D.-W. Zhang1, M.-C. Cui, M. Cao, N.-Y. Ben, S.-D. Zhao. Int. J. Adv. Manuf. Technol. 91 (9-12), 3823 (2017). Crossref

10. W. Wilson, S. Sheu. International Journal of Mechanical Sciences. 30, 7 (1988). Crossref

11. A. Milenin, X. Dyya, Z. Muskalski, Ya. Pilyarchik. Metizy. 2, 30 (2006). (in Russian) [А. Миленин. Х. Дыя, 3. Мускальски, Я. Пилярчик. Метизы. 2, 30 (2006).]

12. A. Zinutti, D. Saro. Metizy. 1, 37 (2009). (in Russian)
[А. Зинутти, Д. Саро. Метизы. 1, 37 (2009).]

13. A. I. Rudskoy, V.A. Lunev, O.P. Shaboldo. Volocheniye. St. Petersburg, Polytechnic University Press (2011) 126 p. (in Russian) [А. И. Рудской, В. А. Лунев, О. П. Шаболдо. Волочение. С.-Петербург, Издательство Политехн. университета (2011) 126 с.]

14. V.F. Danenko, B.N. Zamotayev, I.S. Kovalenko, K. V. Zmeychuk. Technical science. Geology. 4 (5), 47 (2016). (in Russian) [В.Ф. Даненко, Б.Н. Замотаев, И. С. Коваленко, К.В. Змейчук. Технические науки. Геология. 4 (5), 47 (2016).]

15. A. N. Abramov, D. G. Tyulenev, N.A. Filippova. KShP OMD. 5, 13 (2014). (in Russian) [A.Н. Абрамов, Д.Г. Тюленев, Н.А. Филиппова. КШП ОМД. 5, 13 (2014).]

16. V.Yu. Sholom, V.S. Zhernakov, A.N. Abramov. KShP OMD. 4, 10 (2016). (in Russian) [В.Ю. Шолом, В.С. Жернаков, А.Н. Абрамов. КШП ОМД. 4, 10 (2016).]

17. I. L. Perlin, M.Z. Ermanok. Teoriya volocheniya. Moscow, Metallurgiya (1971) 448 p. (in Russian) [И. Л. Перлин, M.3. Ерманок. Теория волочения. Москва, Металлургия (1971) 448 с.]

18. F. K. Ivanchenko et al. Calculations of the load-lifting and transporting cars. Kiev, Vishcha shkola (1978) 576 p. (in Russian) [Ф.К. Иванченко и др. Расчеты грузоподъемных и транспортирующих машин. Киев, Вища школа (1978) 576 с.]

19. L. Ya. Perel. Spravochnik. Moscow, Mashinostroyeniye (1983) 543 p. (in Russian) [Л.Я. Перель. Справочник. Москва, Машиностроение (1983) 543 с.]

20. V.K. Potemkin, V.P. Polukhin, Ya.D. Vishnyakov et al. Ferrous metallurgy. 6, 65 (1975). (in Russian) [В. К. Потемкин, В.П. Полухин, Я.Д. Вишняков и др. Черная металлургия. 6, 65 (1975).]

21. X. Khartman, V.P. Polukhin, V.K. Potemkin. Izvestiya. Ferrous metallurgy. 5, 62 (1981). (in Russian) [Х. Хартман, В.П. Полухин, В.К. Потемкин. Изв. Вуз. Черная металлургия. 5, 62 (1981).] 